\title{
Effect of Age, Gender, Side and Impaction Types on Surgical Difficulty During Mandibular Third Molar Extraction
}

\author{
Krishna Gopal Bhuju', Sujita Shrestha', Riwaj Kaki ${ }^{\text {and Sameer Aryal }}{ }^{1}$
}

\author{
1Department of Dental Surgery, Nepalese Army Institute of Health Sciences, Shree Birendra Hospital, \\ Chhauni, Kathmandu, Nepal \\ ${ }^{2}$ Kantipur Dental College, Basundhara, Kathmandu, Nepal
}

\begin{abstract}
Introduction: This study was conducted to assess the relationship of patient's age, gender, side and impaction types to surgical difficulty during mandibular third molar extraction through the data collected over a period of one year by single maxillofacial surgeon. All the extractions were performed under the same environment and conditions.

Methods: Descriptive clinical study of 401 patients was carried out between the ages of 16 to 45 years. Age, gender, impaction side and impaction types (according to the Winter classification) were recorded on proforma. Duration of surgery for each patient was recorded after starting incision to the completion of suture which was divided into less than 10 minutes (mild), 11 to 20 minutes (moderate) and above 21 minutes (severe). Pearson's Chi-square test was used for data analysis and significance level was less than or equal to 0.05 .

Results: Among 401 participants, 225 (56.1\%) were male and 176 (43.9\%) were female. Mean age was 31.5 years and mean operation time was 17.59 minutes. After statistical analysis there was a significant correlation among gender and side of impaction where $p$ value is 0.043 and 0.048 respectively.

Conclusions: There is a statistically significant correlation between gender and side of impaction with duration of surgery which is considered as the objective measure of surgical difficulty whereas age and impaction types didn't show any significant correlation.
\end{abstract}

Keywords: extraction; mandibular third molar; surgical difficulty

Correspondence: Krishna Gopal Bhuju, Department of Dental surgery, Nepalese Army Institute of Health Sciences, Shree Birendra Hospital, Chhauni,Kathmandu, Nepal. Email: drbhuju@gmail.com

DOI: http://dx.doi.org/10.3126/mjsbh.v17i1.18950

Submitted on: 2018-01-07

Accepted on: 2018-02-18 


\section{INTRODUCTION}

Most frequently occurring tooth impaction is the mandibular third molar due to inadequate space in the mandible. Impaction may lead to pericoronitis, caries on an adjacent tooth and development of cystic lesions. ${ }^{1,2}$ Extraction of third molar is the most common straight forward and low morbidity dentoalveolar surgery performed by oral surgeon in the clinic.3,4 The difficulty of surgical removal will vary from routine mild discomfort to complex condition requiring hospitalization which may cause permanent damage to adjacent structures. ${ }^{5}$ An association between increased surgical difficulty and prolonged recovery with different types of complication has been reported. ${ }^{3}$ Post-operative complications are affected by patient, tooth related and operative factor.6,7 Age, gender, built, habits, size and oral hygiene status are the patient factors. Type of impaction, depth of impaction, presence of infection, morphology of roots, relation to inferior alveolar nerve, and associated pathology are the tooth related factors. Surgeon's experience, surgical time, use of drugs, type and extent of incision and wound closure are the operative factors. In this study, different variables of all three factors are enrolled.

Time taken for extraction of third molar has been considered as the gold standard in calibration of surgical difficulty which is directly proportionate to the postoperative complications except in anxious and hyperactive patient. 8,9 Duration of surgery is recorded differently, some authors record after the start of bone cutting to the end and others record from start of incision to the last suture. ${ }^{6}$ Duration of surgery has been affected by the patient factors like age, sex, built and radiographic factor like angulations in terms of their position namely; vertical, horizontal, mesioangular and distoangular. ${ }^{10,13}$ Most of the authors believe that there is a relation between surgical difficulty and radiographic factors such as type and depth of impaction and number of roots $2,9,12,13$ but the correlation between patient factors and surgical duration is still a controversy.2,6,7,9 Removal of the impacted teeth is more difficult with advancing age. ${ }^{1}$ Younger patients will have relatively soft and more resilient bone whereas older patients will have stiff and harder bone. Bone removal in older patients during surgery require more time and amount of bone removal is also more, resulting in more post-operative complications 6,8 however one study showed that there is no significant difference between postoperative complications following surgical extraction between patient age up to 40 years and those above 40 years. ${ }^{14}$

There are multiple studies conducted about patient factors, difficulty in surgery and different types of complications. There is a wide variation and controversy among them. There should be scientific reliable methods to assess between age, gender, impaction type to the surgical difficulty so that appropriate triage of difficult third molar impaction can be made easily by general dental practitioner and refer them to consultant oral surgeon if required. No such studies have been done in Nepal. The purpose of the present study is to assess the relationship of patient age, gender, impaction side, impaction type to the surgical difficulty in terms of duration of surgery.

\section{METHODS}

This is the descriptive clinical study carried out in tertiary care centre in Nepal from July 2015 to June 2016. All the patient who gave consent and were fit for extraction under local anesthesia were selected. Age, gender, impaction side of each patient were recorded on proforma. All the patients aged between 16 to 45 years were included and they were further divided into the younger group 16 to 30 years and older group 31 to 45 years. A standard periapical radiograph was taken to determine the 


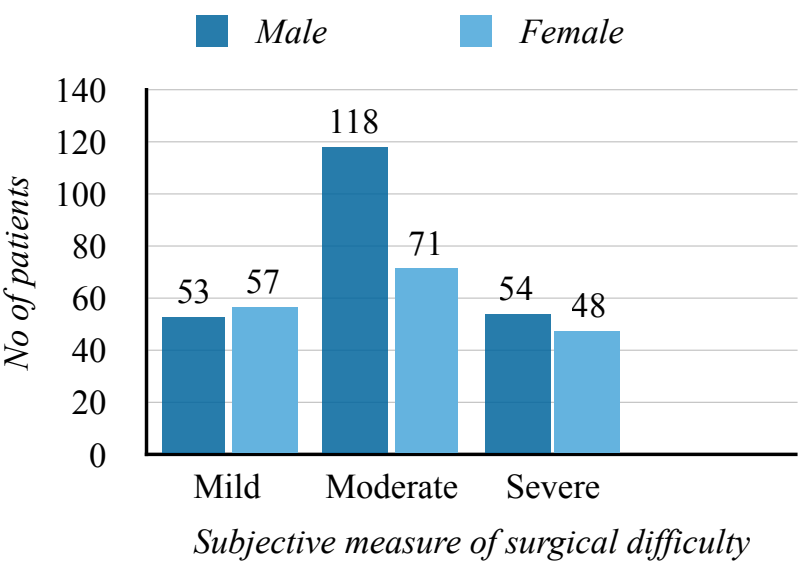

Figure 1. Relationship between gender and surgical difficulty

angulation of impaction according to Winter classification.

All surgeries were performed by the same maxillofacial surgeon under the same condition and environment. Local anesthesia was achieved by $2 \%$ xylocaine with 1:80,000 adrenaline. A full thickness three sided mucoperiosteal flap was raised with the mesial relieving incision at the distal side of the standing second molar. Buccal guttering osteotomy was performed by using straight micro motor hand piece with straight fissure bur under continuous irrigation of normal saline. The tooth was extracted using straight Couplan elevator and whenever required sectioned by bur and removed by elevator. Flap repositioning and suturing was done by 3 ' 0 ' silk after thorough irrigation and toileting of socket At the end of the surgery, all the patients were duly instructed with post extraction instructions and prescribed oral medications; amoxycillin $500 \mathrm{mg}$ TDS, metronidazole $400 \mathrm{mg}$ TDS, and serratopeptidase $10 \mathrm{mg}$ TDS for 5 days. Brucet (combination of paracetamol $1000 \mathrm{mg}$ and ibuprofen $343 \mathrm{mg}$ ) TDS for 3 days was given and then as per requirement. The time taken for extraction was considered as the objective measure of surgical difficulty and was recorded after starting incision to the completion of suturing in minutes. Difficulty of surgery was

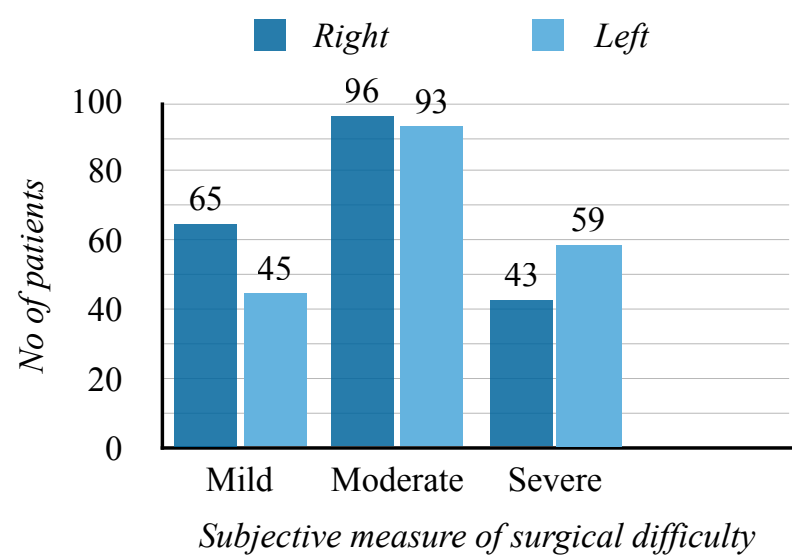

Figure 2. Relationship between side of impaction and surgical difficulty

grouped into three categories; mild less than 10 minutes, moderate 11 to 20 minutes and severe above 21 minutes.

Statistical Package for Social Sciences (SPSS) version 20 was used for data analysis. The results of the Pearson Chi-Square test were used to determine the relationship between patient factors; age, gender, side and impaction type with duration of surgery or surgical difficulty as the dependable variable. Statistical significant level was set at $p \leq$ 0.05 .

\section{RESULTS}

The total of 500 patients were referred for impacted third molar extraction during the study period. Only 401 patients were fit to be enrolled in the study. Among them 225 (56.1\%) patients were male and $176(43.9 \%)$ were female. Operation time ranged from 8-45 minutes with mean time 17.59 minutes (Standard deviation 7.15).

Analysis of patient factors; age, gender, side and impaction types with surgical time by Pearson ChiSquare test revealed that only gender and side of impaction had statistical significance correlation with surgical time with $\mathrm{p}$ value being 0.043 and 0.048 respectively (Table 1). The relationship between gender and surgical difficulty is shown in figure 1 . Male patients were predominantly difficult 
Table 1: Chi square test between patient factors and surgical difficulty

\begin{tabular}{|c|c|c|c|c|c|c|}
\hline \multicolumn{2}{|c|}{ Variables } & \multicolumn{3}{|c|}{ Duration of Surgery in Minutes } & \multirow[t]{2}{*}{ Total } & \multirow[t]{2}{*}{ p Value } \\
\hline & & Less than10 & Less than 11 & Above 21 & & \\
\hline \multirow[t]{3}{*}{ Gender } & Male & $53 / 23.6 \%$ & $118 / 52.4 \%$ & $54 / 24 \%$ & $225 / 100 \%$ & \multirow[t]{3}{*}{0.043} \\
\hline & Female & $57 / 32.4 \%$ & $71 / 40.3 \%$ & $48 / 27.3 \%$ & $176 / 100 \%$ & \\
\hline & Total & $110 / 27.4 \%$ & $189 / 47.1 \%$ & $102 / 25.4 \%$ & $401 / 100 \%$ & \\
\hline \multirow[t]{3}{*}{ Age in years } & $16-30 \mathrm{yrs}$ & $66 / 29.5 \%$ & $99 / 44.2 \%$ & $59 / 26.3 \%$ & $224 / 100 \%$ & \multirow[t]{3}{*}{0.396} \\
\hline & $31-45$ yrs & $44 / 24.9 \%$ & $90 / 50.8 \%$ & $43 / 24.3 \%$ & $177 / 100 \%$ & \\
\hline & Total & $110 / 27.4 \%$ & $189 / 47.1 \%$ & $102 / 25.4 \%$ & $401 / 100 \%$ & \\
\hline \multirow{3}{*}{$\begin{array}{l}\text { Side of } \\
\text { impaction }\end{array}$} & Left & $45 / 22.8 \%$ & $93 / 47.2 \%$ & $59 / 29.9 \%$ & $197 / 100 \%$ & \multirow[t]{3}{*}{0.048} \\
\hline & Right & $65 / 31.9 \%$ & $96 / 47.1 \%$ & $43 / 21.1 \%$ & $204 / 100 \%$ & \\
\hline & Total & $110 / 27.4 \%$ & $189 / 47.1 \%$ & $102 / 25.4 \%$ & $401 / 100 \%$ & \\
\hline \multirow{5}{*}{$\begin{array}{l}\text { Type of } \\
\text { impaction }\end{array}$} & Mesioangular & $49 / 29.3 \%$ & $79 / 47.3 \%$ & $39 / 23.4 \%$ & $167 / 100 \%$ & \multirow[t]{5}{*}{0.078} \\
\hline & Horizontal & $29 / 30.2 \%$ & $35 / 36.5 \%$ & $32 / 33.3 \%$ & $96 / 100 \%$ & \\
\hline & Distoangular & $0 / 0.0 \%$ & $7 / 77.8 \%$ & $2 / 22.2 \%$ & $9 / 100 \%$ & \\
\hline & Vertical & $32 / 24.8 \%$ & $68 / 52.7 \%$ & $29 / 22.5 \%$ & $129 / 100 \%$ & \\
\hline & Total & $110 / 27.4 \%$ & $189 / 47.1 \%$ & $102 / 25.4 \%$ & $401 / 100 \%$ & \\
\hline
\end{tabular}

in surgical extraction of impacted third molar. Another statistically significant variable was side of impaction which is shown in figure 2. It implies that left side of extraction is more difficult than right side of impaction.

\section{DISCUSSION}

The present study compared the effects of age, gender, side and angulation of impacted tooth to the operative difficulty which was measured in terms of duration of extraction of impacted tooth as more the duration, more difficult will be extraction. A number of studies have used surgical technic and surgical time as determinants of difficulty. $8,11,16,18$ Clinical as well as radiological findings prior to the surgery will help to correctly plan the surgery and increase the patient's level of satisfaction and decrease the fear and anxiety. There is no common concept about the patient factors which are contributory to the difficult surgery of third molar surgery. Here we compared our findings with some of the previous reports in the literature.

In a recent study, Akadiri OA, Obiechina $\mathrm{AE}^{11}$ reported that demographic, radiographic and surgical variables are strongly associated with surgical difficulty. However no previous study has analyzed the multivariate association among the preoperative factors, surgical difficulties and complications. The duration of surgery as noted previously is considered gold standard for measuring the intraoperative difficulty.9,12 Around half of the surgeries analyzed in this study were categorized as having moderate degree of difficulty. The duration of surgery of this study was 8 to 45 
minutes and mean is 17.88 minutes. Various

duration of operation, 7.74 minutes to 105 minutes has been reported.3,4,6-10,13,15,16 These variations are mainly due to the experience of surgeon and assistant, ${ }^{18}$ definition of operation time, speed of micromotor, sharpness of bur, anxiety, fear, gag reflex, mouth opening 19 and overall condition of facilities used.

Statistically significant patient factors correlated with surgical difficulty in our study were gender and side of impaction. Gender is one of the predictors of difficulty of impacted third molar surgery. ${ }^{17,19}$ There is a statistically significance relation between gender and surgical duration which was also noted in the study undertaken by Susarla and Dodson ${ }^{16}$ and Sundus AM, Maha MA, Khawlah TH,Ahmed SA. ${ }^{19}$ However many studies are not in favor of this.4,8-11,15 More frequent and late complications are associated with longer duration of surgery in female population. ${ }^{4}$ Large sizes of the crown, roots, thick buccal pad of fat might lead to more difficult third molar extraction of men than women.

Side of impaction of third molar tooth also has statistical significant correlation with surgical duration. This is mainly due to the advantage of right handed surgeon, which makes it easy to retract cheek and elevate the tooth while extracting. Kyengluk Park ${ }^{17}$ in study of 762 surgical extraction, showed impaction side in jaw was statistically not significant.

According to many authors, age is the most consistent factor in determination of surgical difficulty because of the difference in bone density. 1,8,9,17 In this study, age was not a statistically significant determinant of surgical difficulty but it may be significant to the occurrence of complications. ${ }^{4}$ Renton T, Smeeton N and McGurk $\mathrm{M}^{15}$ showed that patient age was relevant for predicting the difficulty of third molar extraction. But Susarla and Dodson ${ }^{16}$ and Ricardo and Belmiro ${ }^{10}$ showed that age was not statistically associated with surgical difficulty or surgical time. The positive relation of age with surgical duration may be due to bone density, complete root formation and ankylosis of third molar as age advances.

Prevalence of impaction types of teeth is in decreasing order from mesioangular, vertical, horizontal and distoangular in this study. James $\mathrm{R}$ Hupp ${ }^{1}$ reported the same series of prevalence with difficulty in extraction also. However in this study type of impaction was not statistically significant with duration of surgery. Many authors asserted that position of impacted tooth directly influenced in difficulty of extraction.8-10,12,16,18,19 However Renton T, Smeeton N and McGurk M15 didn't agree that spatial orientation of tooth may cause surgical difficulty instead they identified bony impaction as the cause of surgical difficulty. In fact the radiographic factors such as angulation, depth of impaction, relationship with ramus, root formation and morphology of root have been considered the factors which affect the difficulty of third molar surgery. 10,12

There are many factors which affect the surgical difficulty in impacted third molar extraction. Age, gender, side, Body Mass Index, ethnicity, operator experience, method of extraction, depth of impaction, ramal relation, angulation, development of root, root curvature, relationship to the mandibular canal, width of root, anxiety of patient, fear, gag reflex, mouth opening, and many other factors influenced the difficulty in extraction of third molar, however there is a variability among the researchers about their relative impacts in surgical extraction of impacted mandibular third molar. ${ }^{3,8-19}$ 


\section{CONCLUSIONS}

This study showed that there is a statistically significant correlation between gender and side of impaction with duration of surgery which is an objective measure of surgical difficulty, whereas age and impaction types didn't show any significant correlation. The study also revealed the prevalence of impaction types of mandibular third molar tooth is in decreasing order from mesioangular, vertical, horizontal and distoangular impaction.

To cite this article: Bhuju KG, Shrestha S, Karki R, Aryal S. Effect of age, gender, side and impaction types on surgical difficulty during mandibular third molar extraction. MJSBH. 2018;17(1):11-7.

Conflict of Interest: None declared

\section{REFERENCES}

1. James RH, Edward E, Myron RT. Principles of management of impacted teeth. Contemporary oral and maxillofacial surgery. vol 6. Elsevier, Mosby, pp 143-167(2008)

2. Shital P, Saloni M, Faizan S, Taksh S. Impacted Mandibular Third Molars; A Retrospective Study of 1198 Cases to Assess Indications for Surgical Removal and Correlation with Age, Sex and Type of Impaction, A Single Institutional Experience. J. Maxillofac Oral Surg. Jan-Mar 2017 16(1):79-84.

DOI 10.1007/s12663-016-0929-z

3. Nurgul K, Mehtap M, Betul T, Umit S. Difficulty of Impacted Mandibular Third Molar Tooth Removal: Predictive Ability of Senior Surgeons and Residents. American Association of Oral and Maxillofacial Surgeons. J Oral MaxillofacSurg 72:1062.e1-1062.e6, 2014

DOI: http://dx.doi.org/10.1016/j.joms.2014.01.023

4. Ziad M, Mahmoud K. Al-Omiri, Ameen K. Risk Indicators of Postoperative Complications following Surgical Extraction of Lower Third Molars,Med PrincPract 2011;20:321-325

DOI: $10.1159 / 000324550$

5. Nelson-Luis BR, Ana-Carolina T, Cássia CM, Jaina O, Rafaela S. Factors associated with complications of removal of third molars: A transversal study. Med Oral Patol Oral Cir Bucal. 2011;16 (3):376-80.

DOI: http://dx.doi.org/doi:10.4317/medoral.16.e376

6. Seidu AB, Wasiu LA, Babatunde OB, Emeka VO and Ademola AA. Effect of age, impaction types and operative time on inflammatory tissue reactions following lower third molar surgery. Head \& Face Medicine. 2011;7:8.

DOI: http://www.head-face-med.com/content/7/1/8

7. Otasowie D, Osunde Birch D, Saheeb. Effect of Age, Sex and Level of Surgical Difficulty on Inflammatory Complications After Third Molar Surgery . J. Maxillofac Oral Surg. 2015;14(1):7-12. DOI:10.1007/s12663-013-0586-4

8. Gbotolorun OM, Arotiba GT, Ladeinde AL. Assessment of factors associated with surgical difficulty in impacted mandibular third molar extraction. J Oral Maxillofac Surg. 2007;65:1977-1983. 
DOI: 10.1016/j.joms.2006.11.030.

9. Obimakinde OS, Okoje VN Olabode A Ijarogbe, AM Obimakinde. Role of Patients' Demographic Characteristics and Spatial Orientation in Predicting Operative Difficulty of Impacted Mandibular Third Molar.Ann Med Health Sci Res. 2013; 3(1): 81-4.

DOI:10.4103/2141-9248.109512

10.Carvalho RW, Vasconcelos BC. Assessment of factors associated with surgical difficulty during removal of impacted lower third molars. J Oral Maxillofac Surg. 2011;69:2714-21.

DOI:10.1016/j.joms.2011.02.097

11. Akadiri OA, Obiechina AE. Assessment of difficulty in third molar surgery-A systematic review. J Oral MaxillofacSurg. 2009;67:771.

DOI: $10.1016 /$ j.joms.2008.08.010.

12. Yuasa $\mathrm{H}$, Kawai T, Sugiura M. Classification of surgical difficulty in extracting impacted third molars. $\mathrm{Br}$ J Oral Maxillofac Surg. 2002;40:26-31.

DOI:10,1054/bjom.2001.0684.

13. Samir M, Abdul M, Seema AH, Mohammed A, Zahir H. Mandibular third molar impactions in male adults: Relationship of Operative time and Types of impaction on inflammatory complications. J Int Oral Health. 2014; 6(2): 9-15.

14. Adeyemo WL, Ogunlewe MO, Ladeinde AL, Hassan OO, Taiwo OA. A Comparative Study of Surgical Morbidity Associated with Mandibular Third-Molar Surgery in Young and Aging Populations. J Contemp Dent Pract. 2010; 11(4):001-008.

DOI: http://www.thejcdp.com/journal/view/volume11-issue4-adeyemo

15.Renton T, Smeeton N, McGurk M. Factors predictive of difficulty of mandibular third molar surgery. Br Dent J. 2001;190:607-9.

DOI:10.1038/sj.bdj.4801052a

16. Susarla SM, Dodson TB. Estimating third molar extraction difficulty: a comparison of subjective and objective factors. J Oral Maxillofac Surg. 2005 Apr;63(4):427-34.

DOI: http://dx.doi.org/10.1016/j.joms.2004.12.003

17.Park KL. Which factors are associated with difficult surgical extraction of impacted lower third molars? J Korean Assoc Oral MaxillofacSurg. 2016;42:251-258.

DOI: https://doi.org/10.5125/jkaoms. 2016.42.5.251

18. Susarla SM, Dodson TB. Risk factors for third molar extraction difficulty. J Oral Maxillofac Surg. 2004;62:1363-71.

DOI:10.1016/j.joms.2004.05.214

19. Sundus AM, Maha MA, Khawlah TH, Ahmed SA. Factors predictive of difficult impacted third molar surgery. The N Iraqi J Med. 2013; 9(2). 